\title{
OS ESTUDOS DE RICARDO CARVALHO CALERO SOBRE ROSALÍA DE CASTRO: UNHA ACHEGA MAXISTRAL
}

\author{
THE STUDIES OF RICARDO CARVALHO CALERO \\ ON ROSALÍA DE CASTRO: A MASTERFUL CONTRIBUTION

\section{María Pilar García Negro Universidade da Coruña}

\begin{abstract}
Resumo: Ricardo Carvalho Calero aúna na súa personalidade a condición de escritor de creación e a de científico. Ambas as dimensións revélanse óptimas para o tratamento rigoroso e innovador de Rosalía de Castro como grande escritora galega e universal. Ela é tratada como un clásico e como a creadora da literatura galega contemporánea: unha intelectual ao servizo da lingua e da patria galega, cuxo talento artístico e audacia innovadora aprofundan nas máis transcendentes perguntas da condición humana e do sentido da historia. Carvalho Calero é o autor primeiro e primordial en abordar a investigación rigorosa e integral da obra da escritora, labor que callou na súa tese de doutoramento, no discurso de ingreso na Real Academia Galega, na historia da literatura e en centos de colaboracións xornalísticas e discursivas, con particular incidencia no ano 1985, en que se conmemorou o centenario do falecemento de Rosalía de Castro. A dedicación rosaliana de Carvalho Calero é constante ao longo de toda a súa vida. Todo canto se escrebeu sobre a autora con posterioridade á achega de Carvalho Calero parte inequivocamente desta base e deste edificio de hermenéutica rosaliana, que abre o camiño, asemade, a novas perspectivas de abordaxe e interpretación da obra da escritora.
\end{abstract}

\begin{abstract}
The personality of Ricardo Carvalho Calero combines the status of a creative writer and that of a scientist. Both dimensions are optimal for the rigorous and innovative analysis of Rosalía de Castro as a great Galician and universal writer. She is approached as a classic writer and as the creator of contemporary Galician literature: an intellectual at the service of the Galician language and the Galician nation, whose artistic talent and innovative audacity delve into the most transcendent questions of the human condition and meaning of history. Carvalho Calero is the first and foremost author to address
\end{abstract}


the rigorous and comprehensive research of the writer's work, an endeavour that culminated in his doctoral dissertation, his induction speech for the Royal Galician Academy, his Historia da literatura galega contemporánea [History of Contemporary Galician Literature] and hundreds of pieces of journalism and public speeches, especially in 1985, when the centenary of the death of Rosalía de Castro was commemorated. Carvalho Calero's interest in Rosalía de Castro is constant throughout his life. Everything that was written about the author after Carvalho Calero's contribution is unequivocally based on his work and on this construction of a hermeneutics for de Castro's production, which also opens the way to new perspectives on approaching and interpreting the writer's work.

Palabras chave: Rosalía de Castro, Ricardo Carvalho Calero, rosalianismo, poeta xenial, achega maxistral, abordaxe científica, innovación.

Key words: Rosalía de Castro, Ricardo Carvalho Calero, de Castro studies, great poet, masterful contribution, scientific approach, innovation.

\section{UNHA ENCICLOPEDIA ROSALIANA}

Son centos de páxinas as dedicados por Ricardo Carvalho Calero ao estudo, análise, interpretación e divulgación de Rosalía de Castro. Tal dedicación é unha recorrencia ao longo de toda a súa vida e coñeceu múltiplos formatos e suportes, desde o académico de maior categoría - a tese de doutoramento- até o artigo xornalístico de ampla difusión, pasando, claro está, polo asento científico da historia da literatura contemporánea, por edicións da súa obra e polas colaboracións en revistas especializadas, congresos ou palestras de todo tipo. A escritora fai parte das súas primeiras leituras e ela acompañarao na súa despedida da vida: o derradeiro artigo por el escrito tena a ela por obxecto ${ }^{1}$, no cerramento dun círculo que podemos dar por comezado no poema "Madrigal a Rosalía", publicado no seu $\mathrm{O}$ silenzo axionllado, de 1934, e incluído así mesmo na colectánea Pretérito imperfeito (1927-1961), sob o título $O$ siléncio ajoellado, e mais pola redacción dunha nota crítica sobre "Rosalía, Curros e Juan Ramón" (publicada en Nós 136, 15 de abril de 1935). 55-56 anos separan esta homenaxe poética e esta nota crítica do artigo

1 Trátase do artigo "Falta um capítulo em El caballero de las botas azules", pedido polo profesor Luís García Soto e entregue a este polo autor en xaneiro de 1990, poucas semanas antes de falecer. Publicouse postumamente na revista Nova Renascença (1999), número dedicado monograficamente ás letras galegas ("Homenagem à Galiza"), organizado e coordenado polo profesor da Universidade de Santiago de Compostela antes mencionado. Publicado tamén recentemente na revista Follas Novas (2020a). 
póstumo que acabamos de mencionar. Neste arco temporal, o escritor fixo de Rosalía de Castro tema de atención constante, tal e como evidencia o estudo bibliográfico recollido polos doutores López e Pociña (2019). Tamén de revisión e de actualización documental e valorativa.

Ora ben, para alén deste caudal cuantitativo -que supera o cento de entradas-, cómpre consignar decontado o valor cualitativo, inaugural, desta bibliografía rosaliana, no que ten de abordaxe científica pioneira, submetendo, pois, a obra da escritora a unha análise e hermenéutica como a dispensada a outros clásicos da literatura universal. Tal perspectiva investigadora supón unha novidade integral nun contexto cultural onde a escritora era máis citada do que lida, máis reverenciada do que coñecida, inclusive máis deformada do que recoñecida na súa verdade textual, e advén, de por parte, no momento histórico oportuno, no medio e medio de todas as inclemencias despersonalizadoras da Galiza, desnacionalizadoras en todos os campos. Referímonos, claro está, á damnatio memoriae reforzada pola segunda ditadura do século XX, de que é vítima o proprio autor e dentro da cal, con fe e perseveranza admirábeis, vai continuar a súa obra de amor e de servizo a Galiza, abruptamente interrompida pola guerra civil española e polo seu desenlace. Situámonos, pois, na década de cincuenta e de sesenta do século pasado, con calquer produto cultural submetido á censura e, no caso galego, cun plus de ignorancia e de estrañamento aínda meirande. Tratábase, logo, de retomar unha dedicación intelectual e patriótica interrompidas, mais non só. Cumpría axir á altura dos tempos, tratando de estudar e interpretar a literatura galega desde as súas claves xenéticas, históricas e estéticas, como un produto xenuíno dun povo que se recoñece a si mesmo como tal a través do instrumento posíbel, a literatura na súa lingua. E é aquí, neste afán, onde a persoa e a obra de Rosalía de Castro se elevan con toda a súa significación e con todo o seu ímpeto.

\section{OS FITOS PRINCIPAIS}

No campo estritamente académico, o camiño rosaliano do noso autor conta cos seguintes fitos principais: o ensaio "Arredor de Rosalía", pertencente ao volume colectivo 7 ensayos sobre Rosalía, editado en 1952 pola recentemente fundada Editorial Galaxia e que convoca no seu elenco elementos galegos, portugueses, literarios, artísticos e filosóficos: proba do relevo concedido á escritora como suxeito central da identidade galega; a tese de doutoramento, defendida na Universidade Complutense de Madrid en 1954; os dous volumes dela derivados, un en galego, outro en español, ambos de 1955; o discurso de ingreso na Real Academia Galega, de 1958; a publicación do primeiro tomo da súa Historia da literatura galega contemporánea, en 1963. Ora, como xa dixemos, a dedicación rosaliana perdurará de por vida e será arrequecida con outras análises e perspectivas, moi atentas, por 
certo, a novas investigacións sobre a escritora e, loxicamente, con novas achegas derivadas da liberación da censura vixente na ditadura.

Canto ao primeiro ensaio citado, cómpre subliñar como el é, realmente, o prototipo de traballos posteriores, o sumario (23 páxinas, 18 subcapítulos) dunha "tese" sobre Rosalía de Castro, no seu primeiro "guión" ou esquema. Hai novidades que convén termos en conta: a razón da ecuación Rosalía de Castro = Galiza; a consideración das súas obras en verso e en prosa; a revolución métrica; a riqueza temática; os grandes fitos da obra galega. Mais hai unha novidade esencial nesta aproximación que será logo utilizada como base literal de desenvolvementos futuros e é a seguinte: a tentativa seria de analisar a escritora en por ela, conforme á súa produción, á súa textualidade, non como motivo de ilustrar teses previas do analista, fosen estas a filosofía da saudade, o intento de abordaxe psicanalítica ou a divinización acrítica.

Na xustificación do tema escollido para o ingreso na Academia (que ten lugar, en feliz premonición, o 17 de Maio de 1958, no 125 aniversario do nacemento de Murguía, 95 anos despois da dedicatoria de Cantares gallegos pola escritora e cinco anos antes de se instituír oficialmente a data do Día das Letras Galegas, precisamente arredor desta semántica rosaliana), o que vai ser novo membro da institución oferece claves significativas da orientación do seu traballo que contribúen a explicar a investigación anterior e a futura. As grandes obras do espírito humano merecen a atención e o pensamento particular de cada época: non se esgotan endexamais, pois, á luz de novos métodos, de novas circunstancias históricas, de novos coñecementos, vanse anovar elas mesmas e posibilitar que cada nova xeración extraia novas luces do seu estudo. En suma, os grandes clásicos nunca acaban de dicer o que teñen que dicer, tal e como Italo Calvino proclamaría moitos anos despois (1991). Esta é a primeira razón de elexer Rosalía de Castro como obxecto do seu discurso. A segunda tamén ten a ver con argumentos usados polo escritor italiano no seu célebre Por que ler os clásicos: pola súa profunda galeguidade e pola súa universalidade xenuína, a escritora, "cume elevadísimo da literatura europea”, debe ser obxecto primordial de pescuda para os proprios galegos, non só polo seu valor intrínseco, senón porque estudala a ela é estudarnos nós mesmos. Fainos moita falta coñecérmonos, porque como, se non, poderemos actuar no mundo sen saber quen somos? Galegos somos, afirma, e por iso nada rosaliano nos é alleo: "Rosalía, como todo poeta xenial, é un tema que endexamáis se esgota" (Carballo 1959, p. 12).

Eis as credenciais do novo académico, que revalida con este ingreso as proposicións desenvolvidas catro anos antes, na defensa da súa tese de doutoramento (que merecera a máxima cualificación e a concesión de premio extraordinario), a primeira en termos absolutos da universidade española dedicada á literatura 
galega contemporánea. A censura obrigada non impede a declaración dunha ligazón esencial: a escritora é elemento central da personalidade nacional, colectiva, galega. Existe, porque existe o povo galego. O título do discurso é Contribución ao estudo das fontes literarias de Rosalía e constitúe de certo unha monografía de alcance biobibliográfico que contén moito máis do anuncia o título, para alén de realizar un seguimento exhaustivo de leituras, influencias e diálogo da obra rosaliana con múltiplas referencias doutras literaturas, tanto clásicas como modernas. Tema tal só podía ser abordado e desenvolvido por un posuidor, como Carvalho, dun caudal enorme e variado de leituras, para alén dun auténtico persecutor erudito da bibliografía existente sobre a escritora, en calquer lingua. Admira a comprobación -sempre con verificación documental- da enorme e heteroxénea cultura literaria de Rosalía de Castro, así como a superación cualitativa que a obra dela supón verbo de modelos ou fontes de referencia (sirva como exemplo senlleiro o celebérrimo poema "Cando penso que te fuches", que evoca nos seus elementos externos os utilizados por Aurelio Aguirre no poema "El murmullo de las olas"). Ten así mesmo grande valor a desmontaxe de preconceitos ou tópicos deformadores de que a persoa e a obra da autora eran obxecto, por exemplo, a dependencia autoral do seu esposo, Murguía, ou a radical diferenza e superioridade a respeito de Bécquer. No primeiro caso, Carvalho cita á mantenta o artigo "Las literatas", como refutación da autora en vida do vello preconceito sexista. No segundo caso, após rexistar con afán microscópico afinidades, semellanzas e pegadas becquerianas na poesía rosaliana, moitas delas coincidencias epocais, detense en esclarecer a profunda diferenza que separa un e outra, en termos de espectro lírico, densidade de pensamento e de sentimento e, en suma, de transcendencia. Aponta xa unha idea fulcral, que, de ser atendida e entendida, tería aforrado moitas confusións e delicuescencias críticas posteriores. É a que afirma que a concepción da vida rosaliana non é sentimental, senón que está presidida por unha cruel luz intelectual que subliña sen piedade as sombras da existencia. Salienta como en Follas novas e, tamén, no seu derradeiro libro, En las orillas del Sar, Rosalía defronta os misterios da vida e da morte desde un plano de elevada universalidade, e defróntaos cunha tremenda falta de prexuízos. Así conclúe o capítulo XI deste discurso:

Hai, pois, en Rosalía, metafísica onde en Bécquer hai erotismo elexíaco; pensamento onde no sevillán, música; autenticidade onde en Gustavo Adolfo sumisión aos convencioalismos sentimentás; forza onde nil hai esmaio. A poesía de Bécquer e indubidabremente máis doada. Mesmo cando quixo, Rosalía, no terreo da música, ensaióu con asombroso éisito orquestracións wagneriás que esixen un dominio da métrica que o andaluz non probóu. É certo que Bécquer 
morréu novo -Rosalía tampouco morréu vella-; pero hai que xulgalo pola obra que deixóu. Ísta, como lírica -é decir, espresión poética de esperiencias persoás- non pode se comparar en profondidade coa obra da galega. Esaxerando un pouco, diréi que, pra gostar plenamente de ambos, a Bécquer hai que leelo máis ben aos dazaoito anos; a Rosalía, máis ben aos oitenta e un. (1959, p. 67).

Demorámonos neste ponto, pois, por incríbel que pareza, chega aos nosos días tal homologación imposíbel entre o escritor español e a escritora galega, non só en libros de texto ou vulgaridades mediáticas senón en aproximacións pretensamente solventes do ponto de vista académico. Neste importante discurso carvalhiano, fican claras tamén fontes cuxa citación aparece por vez primeira, acompañadas das probas correspondentes. Tal é o caso de Hoffmann ou George Sand, Cervantes ou Lamartine, Madame Staël ou Chateaubriand, Safo ou fontes bíblicas, Petrarca ou Santa Teresa de Jesús, Shakespeare ou San Juan de la Cruz, Victor Hugo ou Miss Cummins... Abano literario-cultural tan amplo como o detectado polo investigador abondaría para desterrar de vez o intereseiro preconceito que predica o espontaneísmo da escritora, a súa falta de cultura formal ou o seu ensimesmamento local.

A mesma observación farémola verbo do volume Sete poetas galegos, publicado por Galaxia en 1955, ou de Aportaciones a la literatura gallega contemporánea, editado por Gredos no mesmo ano. Queremos con esta recordación indicar que, desde data tan antiga, no ecuador da década de 50 do século XX, existen, en selos editoriais perfeitamente accesíbeis, en galego e en español, unha base de coñecemento, documentación e avaliación de Rosalía de Castro que, de seren tidas en conta debidamente, terían aforrado moitas ignorancias, fantasías e, mesmo, disparates. As consecuencias perniciosas do desprezo (ou do plaxio non declarado) destes traballos pioneiros ultrapasan con moito o ámbito literario ou académico, pois, tal e como Carvalho lembraba na xustificación do seu discurso de ingreso na Academia Galega, a metonimia Rosalía de Castro-Galiza está servida e, perversamente, a eficacia do discurso represivo-redutor sobre a escritora é solidario do proxectado sobre a Galiza.

En diálogo intratextual do proprio Carvalho, chama a atención, en ambos volumes, a rotundidade libre de todo complexo, de toda cautela españolizada, con que se produce o escritor. Así, escrebe sen paliativos como entre os cantares de Trueba e os rosalianos hai un abismo. Os Cantares gallegos son, no seu xuízo, un monumento máis perenne que o bronce, pois constitúen unha enciclopedia dos sentimentos, das crenzas e da cultura do povo galego con quen se identifica a autora plenamente. Na consideración de Follas novas, subliña como é unha muller 
a que acerta a expresar coa maior enxebreza a máis espida vivencia humana². Afirma sen reservas como o lirismo de Rosalía acada nesta obra rango filosófico e actualidade inmortal. Admira a clareza dos xuízos, en desafío aberto á orde ideolóxico-relixiosa dominante a aquela altura. Vexamos un exemplo significativo:

Como non xurda o superhome, a poesía rosaliá será decote a poesía vixente pra o adamida esilado. Só debe ser engadido que iste pesimismo, iste escepticismo son enteiramente alleos ao esprito estoico e ao esprito cristián, que salvan ao home en sí mesmo ou en Deus. Na poesía de Rosalía non hai salvación pra o home. As alusións a divindade son enigmáticas ou contradictorias, como pode comprobar todo o que se moleste en acoutar as pasaxes pertinentes na obra da nosa escritora (Carballo 1955a, p. 31).

Tamén adianta como as semellanzas que se poden atopar entre Follas novas e as Rimas becquerianas teñen escasa significación:

Fora de certas afindades formás, Bécquer é un poeta moito menos intelixente e profondo que Rosalía, o seu mundo é moito máis limitado, os seus motivos líricos menos esenciás e a súa actitude ante a vida moito menos baril (Carballo 1955a, p. 33).

Singulariza así mesmo a escritora dentro do grupo de conxéneres do seu tempo (Gertrudis Gómez de Avellaneda, Carolina Coronado ou Christina Georgina Rossetti), con quen non atopa comparanza posíbel, que si admite en ou con Emily Dickinson, aínda carente esta da "intuición ontolóxica" da nosa compatriota. Anotaremos como foi o noso autor o primeiro en se ocupar deste xogo de posíbeis concomitancias ou diferenzas, como o primeiro en traducir ao galego un poema de Dickinson que evoca, co seu hóspede branco, a negra sombra rosaliana.

A redacción da magna Historia da literatura galega contemporánea dá a ocasión ao autor de elaborar unha síntese de todo o lido e investigado sobre a materia rosaliana e, ao tempo, concédese o espazo e a liberdade de espraiarse en novas pescudas, como a biográfica ou a atinente á métrica. $\mathrm{O}$ capítulo a ela dedicado subdivídese en quince subcapítulos que abranxen desde a vida até a caracterización da lingua, coa lóxica atención central aos dous grandes poemarios galegos, mais sen esquecer a citación doutras obras e con atención particular á prosa dos

2 Faino no ronsel da definición de Georg Simmel, para quen a muller é o ser propriamente humano, porque mantén a súa substancia nos limites da humanidade, mentres que o home é metade besta, metade anxo. A cita da obra de Simmel, Cultura femenina y otros ensayos (1934), é ben reveladora dunha cultura letrada do autor amplísima e aberta a todo coñecemento e instrución. 
prólogos daqueles e mais do "Conto gallego". Axiña daremos conta das trabes desta achega senlleira, non sen antes lembrarmos como o escritor, no capítulo inicial ("Importancia de Rosalía"), adianta uns cantos asertos fundamentais: Rosalía é o primeiro clásico do século XIX; cos seus Cantares... a literatura renacente contou xa cunha obra mestra; a importancia literaria da escritora sobarda a súa importancia estritamente histórica; está á cabeza non só da súa xeración, senón de toda a compaña de escritores galegos. $\bigcirc$ afán esculcador e avaliador do labor que se impón o autor desta Historia lévao a apurar ao máximo a información exacta sobre todos os datos relativos á súa biografía, con profusión de información topográfica e familiar, sen encobrimentos falsarios (a nai, fidalga solteira; o pai, sacerdote) nen concesións ás lendas de abandono materno, e coa prudencia de anunciar ampliación ou rectificación do exposto cando futuras pescudas así o determinaren.

Hai dous subcapítulos que merecen un comentario particular, a por de breve, por dúas consideracións: unha certa contradición interna entre eles e a utilización parcial e con afán denigratorio que se ten realizado de afirmacións contidas nun deles. Titúlanse "Physis" e "Psyché" e, como estes rótulos indican, vanse ocupar do físico e da psicoloxía da escritora respectivamente. $O$ primeiro abunda na idea da non correspondencia entre o que comunican os retratos conservados da escritora ("groseiramente tallada”) e a finura e elevación do seu espírito. De aquí derivaría a tendencia á idealización, sob diferentes formas, de que sería obxecto en sucesivas representacións artísticas ou iconográficas, o que probaría a certeza de que o aspecto físico da escritora defrauda a expectativa creada. $O$ historiador, que non dubida en cualificar de "prexuizo" a súa impresión, apela á fisiognomía cuxos signos cumpriría interpretar, pois o seu valor simbólico non sempre é intuíbel. Digamos decontado que, nesta valoración, o definido non é o suxeito examinado senón o examinador, quer dicer, é a "ollada" do espectador a que contamina a resultante, non o físico da contemplada. Naturalmente, non existe a menor ligazón entre unha determinada complexión corpórea e unhas capacidades espirituais, creativas ou intelectuais, mais o certo é que a mesma ciencia médica, a aquela altura, manexaba con profusión esta asociación físico-espiritual. Críticos rosalianos posteriores, como Alonso Montero ou Marina Mayoral, reincidiron no mesmo prexuízo ou aínda o amplificaron ${ }^{3}$, co cal falaríamos tamén de débeda epocal e, por suposto, sexista, pola aplicación unilateral ao sexo feminino.

3 A título de exemplo: "Insisto en mi punto de vista de que la decisión de abandonar el gallego no debe interpretarse como una deserción, ya que Rosalía poseía una pobre conciencia de la realidad y de las posibilidades de una cultura en gallego. Es cierto que ella puso sus cimientos, pero sin percatarse seriamente de ello porque su mente no estaba a la altura de los fenómenos politicoculturales que se estaban gestando. Rosalía fue, antes y después de este despiste histórico, una genial intuición poética. En 
Referímonos supra a unha certa contradición do proprio autor. No subcapítulo seguinte, o dedicado, como xa indicamos, á psicoloxía da escritora, o escritor fala de deformacións irresponsábeis, como a que tende a apresentala como a santiña, a nai galega permanentemente adoecida, "a chorar sempre polas mágoas dos seus fillos" (Carballo 1975, p. 157), isto é, dos galegos. O historiador contrapón a este mito, alimentado por nomes ilustres como Valle-Inclán ou Unamuno, a verdade textual dun carácter femente e enérxico que exhibe a correspondencia conservada e, aínda, testemuños elocuentes do seu esposo, de Murguía. Por aquí, por esta ortopedia forzada e forzosa do verdadeiro carácter da escritora (e da súa lóxica propagación autoral á súa obra), tiña aberta a porta o estudoso para pór en cuestión os prexuízos da súa ollada dirixida ao físico, máxime cando insistía unha e outra vez, como xa vimos, no carácter reflexivo, intelixente, da súa posición como autora e, por tanto, da translación á escrita destes atributos:

O seu carácter era enérxico, e os tenros sentimentos que sabe pór na boca das súas heroínas aldeás, non poden anubiar a súa profunda raíz intelectual, que a levou a plantearse ousadamente na súa poesía de temática filosófica os problemas máis graves do mundo metaempírico (Carballo 1979, p. 17).

\section{ALGUNHAS LECCIÓNS SIGNIFICATIVAS DO LEGADO ROSALIANO DE CARVALHO CALERO}

Falamos supra das trabes da grande achega rosaliana na obra do noso escritor. Reducímolas agora a un repertorio de ideas basilares (como complemento das xa

\footnotetext{
su obra de poeta hay, entre otras actitudes, una respuesta a Galicia, respuesta que es la base, en gran parte, de cien años de meditación gallega y por cuyo alcance ni siquiera la gran poetisa se preguntó” (Alonso Montero 1972, pp. 95-96).

Estes asertos non son ocasionais. A “desintelectualización” practicada coa escritora é recorrente: "No hay que ver en Rosalía a un poeta apriorística y cerebralmente empeñado en crear formas y ritmos nuevos. Rosalía, ante todo naturaleza, se encuentra con las formas que sus contenidos reclaman" (Alonso Montero 1969 , p. 24), isto despois de se referir a todas as novidades métricas de En las orillas del Sar sinaladas por Tomás Navarro. Cal é, logo, o "milagre” rosaliano?: "Rosalía debió de ser extraña mujer para muchos de sus contemporáneos. Rosalía es una mujer que no ha heredado nada: ni fortuna, ni hermosura, ni gran posición social, ni apellido. Rosalía, desde esta plataforma, potente si las hay para desde ella perforar la realidad, escribe libros" (Alonso Montero 1969, p. 10).

Marina Mayoral publica La poesía de Rosalía de Castro en 1974, derivada da súa tese de doutoramento sobre a escritora. Na conclusión do extenso estudo, a investigadora incide tamén en como o "verdadero rostro de Rosalía no resulta grato [...] Rosalía era fea, y, además, de una fealdad poco aristocrática" (Mayoral 1974, p. 568). O seu verdadeiro rosto está nos seus versos, que tamén nos dan a coñecer o seu povo. "Así es Rosalía: más fea que la imagen oficial, pero mucho más humana, profunda, entrañable" (Mayoral 1974, p. 569). Ambas as obras e autores beben abondosamente da fonte carvalhiana, con citas ad hoc ou sen elas. Estendémonos neste excurso para contextualizar un anacronismo-preconceito que ten máis proxenitores que o deostado Carvalho Calero.
} 
debulladas) que xulgamos centrais na orientación debida do papel da escritora e que supoñen, de certo, un decisivo avanzo no coñecemento non só da súa personalidade e da súa obra senón, por lóxica metonimia, da literatura galega toda e, aínda, do proprio país. Elas son:

1. O móbil principal da escrita de Cantares gallegos é a reivindicación patriótica.

2. O prólogo desta obra e o de Follas novas son ensaios.

3. Rosalía de Castro domina soberanamente a materia que trata. A súa socialización infantil na aldea, no campo galego, en contacto directo co povo, permitiulle penetrar profundamente en todos os aspectos da vida, da socioloxía, da psicoloxía, da cultura popular. Mais Cantares... non callaría como literatura perdurábel se a poeta non estivese dotada dunha intelixencia e unha sensibilidade claramente excepcionais.

4. É a súa unha poesía nacional no senso de popular, unha poesía social, democrática, contemporánea. Non é a dunha romántica rousseauniana nen a dunha filántropa, senón a dunha poeta profundamente imbricada na apoloxía do povo a que se sente pertencer. É, pois, corroborante da conciencia galega.

5. Con todos os seus castelanismos (léase: os xa presentes naquela sincronía do galego), a lingua de Rosalía é extraordinariamente expresiva. Na súa poética, revela un manexo fluído de múltiplas formas métrico-estróficas populares, tradicionais, cultas e combinacións orixinais proprias.

6. Follas novas supón a consagración definitiva da autora como poeta total. Superándose a si mesma de xeito asombroso, ensaia a expresión dunha poesía de acento universal en lingua galega. Ela é principio e fin dunha evolución (o vieiro do particularismo e o vieiro do universalismo).

7. Rosalía penetra máis alá das vivencias estéticas e comunica unha visión radical da vida. Non é a súa unha filosofía de salón, como a de Campoamor, senón unha exploración poética do mundo ontolóxico. Filósofos e psicanalistas teñen en Follas novas un campo de acción axeitado. Poesía que comunica moitas ideas sobre a vida e o mundo, sobre a morte, sobre o problema relixioso: a dor universal non se explica en función dunha teodicea, non está xustificada por unha fe viva. Semella como se a escritora prefigurase a conclusión de Sartre de que o home é unha paixón inútil. Mergullada con decisión no océano do ser, non dubida en tornar á superficie cos segredos máis fondos para os expoñer á luz de versos reveladores.

8. A grandeza da poesía rosaliana non está no escolar, senón no persoal; naquilo que non é literatura, senón vivencia. 
9. A crenza segundo a cal as innovacións métricas da escritora foron inconscientes debe ser totalmente desbotada. Revela ao longo de toda a súa obra unha especial destreza como versificadora. Renovou porque quixo renovar e puxo a liberdade de creación e manipulación métrico-estrófica ao servizo do discorrer do seu pensamento. Entre a súa liberdade de pensar e o verso hai, pois, correspondencia visíbel.

10. Conectar o pesimismo rosaliano ou a súa desolación existencial á súa orixe ou a unha patoloxía conxénita carece de todo sentido. É, historicamente, no reino do realismo onde se move; filosoficamente, no das interrogantes profundas, abismáticas, do ser humano.

\section{UNHA DEDICACIÓN ROSALIANA ATÉ A FIN DOS SEUS DÍAS}

A traxectoria do noso escritor é inintelixíbel se non apelamos aos seguintes factores: estamos perante un artista, un creador literario e un científico a partes iguais; tal simbiose continúa (ou emula) a de ilustres artífices da cultura galega do XX como o seu mestre e amigo Otero Pedraio; toda a grande obra carvalhiana dos anos 50, e até o seu falecemento en 1990, é filla dun aprendizado que o marcou de por vida: o alimentado polos seus mestres de Ferrol, polo Seminario de Estudos Galegos e por algunhas aulas universitarias, nun combinado de rigor, apertura intelectual e amor á Galiza que o configurou de por vida; este amor márcase como imperativo dotarse de obras que o certifiquen; o labor científico, en fin, non consiste en reiterar o panexírico ou en repetir reverencias vougas, senón en estudar con toda a obxectividade e todo o entusiasmo unha produción cultural senlleira como foi a literatura galega do XIX e, dentro dela, a da súa artífice principal, Rosalía de Castro.

A dedicación rosaliana de Carvalho Calero explícase por este pano de fundo. Cumpriu sobexamente aquel mandato autoimposto en 1958, en virtude do cal nada rosaliano lle había ser alleo. Así, en 1979 publica Estudos rosalianos, libro que integra unha trintena de traballos espallados en moi diversas fontes. 1985, ano do centenario do falecemento da escritora, é particularmente fecundo en intervencións: inauguración do congreso internacional a ela dedicado; conferencias por múltiplas asociacións culturais do país; artigos en prensa, libros e revistas... Neste ano 1985 abundan as intervencións particularmente felices sobre a escritora, tanto en foros académicos como en múltiplas palestras en asociacións culturais ou en artigos xornalísticos. Como presidente do Congreso Rosalía de Castro e o seu tempo, profere o discurso inaugural, exactamente o día 15 de xullo de 1985, en que se cumprían os cen anos do pasamento da escritora, alocución ante congresistas de 
moitas partes distantes e distintas do mundo. Máis unha vez, salientará o carácter de grande escritora galega e de figura galega universal:

Se a sua voz tem servido aos galegos de lábaro reivindicativo, e as suas inovaçons em matéria de pensamento e métrica a fam umha figura capital na poesia hispánica do século XIX, a sua capacidade para exprimir os desejos e as dúvidas, as senhardades e as angústias do ser humano, além dos acidentes que configuram o nosso documento individual de identidade, situam-na entre as grandes personalidades da literatura mundial, que se caracterizam por ter-nos legado umha mensage inteligível a todas as consciências e traduzível a todos os idiomas (Carvalho Calero 1989, p. 113; García Negro 2020, pp. 209-210).

Ora ben, como xa indicamos, foi decisiva igualmente a súa intervención rosaliana en prensa periódica ao longo deste ano do centenario, nunha sucesión de artigos esclarecedores sobre aspectos cruciais da vida e da obra da escritora (López e Pociña 2019), que terían feliz continuación no ano seguinte, 1986, en que se celebrou o centenario do nacemento de Castelao, o que dá ocasión ao autor para se referir a ambos como unha diarquía no corazón dos galegos. Concluímos, pois, esta nosa aproximación coa reprodución dun destes artigos de vocación e finalidade masiva, o titulado "Rosalia e a nosa identidade", onde fica perfeitamente definida a razón do binomio que o integra:

Rosalia foi a fedatária da identidade de Galiza nos tempos modernos. Non iniciou ela o noso resurgimiento, mas, ao ser o primeiro escritor de valia indiscutível que o Resurgimiento produciu, consolidou un movimento vacilante. Non sabemos se os grandes escritores galegos que a seguiron, terian realizado a sua obra se non os animase tan egrégio precedente.

Mas o feito de que Rosalia dese o pulo definitivo ao noso renacimiento literário, non confina a escritora no campo restrictivamente cultural. Rosalia pode considerar-se como a parteira, se non a nai, da Galiza moderna, en tanto que a sua obra provocou a decisiva recuperazón da nosa consciéncia colectiva.

Ainda que tamén neste aspecto Rosalia tivo os seus precursores, tamén neste aspecto o labor de Rosalia ostenta a primacia na releváncia. Dividido o noso país en dous reinos a partir de Afonso VII, o reino do Norte, vinculado a León e a Castela, foi perdendo o sentido da sua integridade política e cultural, sofreu un proceso lento, mas continuo, de desgaleguizazón, e chegou aos tempos de Rosalia con un turvo sentimento de inferioridade que o abismava na alleazón e o vergoñoso desprezo de si próprio. 
Rosalia escreve Cantares Gallegos para dotar a Galiza de un espello en que se poda ver tal e como é cando non se disfarza: formosa e digna, e non como a ignoráncia e a injustiza dos mais fixeron que ela mesma chegase a imaginar-se. Levanta, pois, Rosalia, acta de verdadeira realidade galega, e levanta-a utilizando o idioma de Galiza, o idioma "que queren facer bárbaro os que non saben que aventaja ás demais línguas en dozura e harmonia”.

Asi que Rosalia expede certificazón da verdadeira personalidade por Galiza. Galiza chegara a Rosalia indocumentada, ou, o que é pior, dotada de unha falsa personalidade. Rosalia, con Cantares Gallegos, a mais antiga obra prima do noso Renacimiento, fornece a Galiza o seu documento nacional de identidade, e Galiza, desde entón, por mui incongruente que a sua conducta poda ser no futuro, dispón de unha cédula persoal, está inscrita no censo dos povos e posui unhas honrosas señas de identidade. Rosalia dá fé da personalidade de Galiza e estende o título de propriedade de Galiza sobre si mesma, sobre a mesma Galiza...

Mas a oficina notarial de Rosalia non remata aqui a expedizón de documentos acreditativos da realidade galega. Follas Novas completa a Cantares Gallegos. Se este livro constitui o documento de identidade colectivo, aquel é o nosso pasaporte para comparecer perante a comunidade internacional da cultura. Agora o galego manifesta-se língua capaz non já de cantar as cousas galegas e subliñar a sua dignidade, mas tamén de dar forma a conceitos poéticos de trascendéncia universal; en fin, de levar o galego alén dos límites administrativos das províncias galegas. A literatura galega subministra un texto á literatura universal.

Devemos, pois, a Rosalia muito mais que unha aportazón valiosa ás nosas letras. Devemos-lle dous documentos fundamentais para a normalizazón da nosa vida colectiva. Cantares Gallegos regista a nosa autenticidade. Follas Novas é o noso título para trascender as nosas fronteiras. Muitas vezes temos manejado con torpidade esa valiosa documentazón. Mas no ámbito doméstico como no exterior, temos un nome, temos un título, temos un creto, temos unha justificazón escrita para sermos e para circularmos no mundo da cultura mercé a Rosalia, que, se non foi a criadora de Galiza, foi a fedatária da sua identidade.

Agradezamos-llo, pois, neste ano do centenário da sua morte, e en todos os anos da nosa vida comun como "célula de universalidade" (La Voz de Galicia 9/ XI/1985; Carvalho 1992, pp. 171-172; 2020b, pp. 121-123).

En entrevistas memorialísticas, el proprio xustificaba esta dedicación continuada: a obra de Rosalía de Castro é unha obra xenial e, aliás, ela, a obra toda, é reivindicativa da nosa cultura, do noso ser colectivo: 
No que ten, pois, de xénio universal como escritora, e no que ten de militante galeguista ao seu modo e no seu tempo, Rosalia -isto último liga-a dunha maneira extraordinariamente forte a toda a história das organizazóns galegas-, no que ten dunha e doutra cousa, é motivo de admirazón e de cariño. E eu, como galego, como escritor e como investigador literário, tiña naturalmente que sentirme extraordinariamente advocado ao estudo da sua obra (Fernán-Vello e Pillado 1986, p. 189).

É o corolario lóxico de quen recoñece que o seu traballo "está dominado intimamente, está edificado, evidentemente, sobre un substrato de entusiasmo polo rexurdimento da nosa cultura e da nosa língua" (Salinas 1991, p. 52). Na edificación da cultura nacional e na normalización da lingua galega cómpre aínda construír moitas e variadas estancias e cómpre fortificalas contra calquer intento de derruba. Neste labor colectivo, a obra extensa, intensa e esclarecedora de Carvalho Calero é axuda impagábel, nesta nosa intervención só ollado á luz do seu contributo imprescindíbel como historiador e crítico literario aplicado a compor a vera effigies dunha grande da nosa historia como Rosalía de Castro.

\section{REFERENCIAS BIBLIOGRÁFICAS}

Alonso Montero, Jesús (1969). Edición, prólogo y notas. En: Rosalía de Castro. En las orillas del Sar. Salamanca: Anaya.

Alonso Montero, Xesús (1972). Rosalía de Castro. Madrid: Júcar.

Blanco, Carmen (1989). Conversas con Carballo Calero. Vigo: Galaxia.

Carballo Calero, Ricardo (1952). Arredor de Rosalía. En: Luís Pimentel et al. 7 ensayos sobre Rosalía. Vigo: Galaxia, [17]-[39].

Carballo Calero, Ricardo (1955a). Sete poetas galegos. Rosalía de Castro, Eduardo Pondal, Manuel Curros Enríquez, Antonio Noriega Varela, Ramón Cabanillas, Luis Amado Carballo, Manuel Antonio. Vigo: Galaxia.

Carballo Calero, Ricardo (1955b). Aportaciones a la literatura gallega contemporánea. Madrid: Gredos.

Carballo Calero, Ricardo (1959). Contribución ao estudo das fontes literarias de Rosalía [Discurso de ingreso]. Lugo: Ediciones Celta.

Carballo Calero, Ricardo (1975). Historia da literatura galega contemporánea. $2^{2}$ ed. Vigo: Galaxia.

Carballo Calero, Ricardo (1979). Estudos rosalianos. Vigo: Galaxia.

Carvalho Calero, Ricardo (1989). Estudos e ensaios sobre literatura galega. Sada:

Ediciós do Castro. 
Carvalho Calero, Ricardo (1992). Umha voz na Galiza. Santiago de Compostela: Sotelo Blanco.

Carvalho Calero, Ricardo (1999). Falta um capítulo em El caballero de las botas azules. Nova Renascença, 72-73, 13-20.

Carvalho Calero, Ricardo (2020a). Falta um capítulo em El caballero de las botas azules. Follas Novas, 4, 160-167. Dispoñíbel en https://follasnovas.rosalia.gal/ artigo/falta-um-capitulo-em-el-caballero-de-las-botas-azules-ricardo-carvalho-calero/

Carvalho Calero, Ricardo (2020b). Umha voz na Galiza. Artigos de jornal (19331989). Escolma. A Coruña: Universidade da Coruña.

Calvino, Italo (1991). Por qué leer a los clásicos. Barcelona: Tusquets.

Fernán-Vello, Miguel A. e Pillado Mayor, Francisco (1986). Conversas en Compostela con Carballo Calero. Santiago de Compostela: Sotelo Blanco.

García Negro, M. Pilar (2011). Ricardo Carvalho Calero: a ciencia ao servizo da nación. Santiago de Compostela: Laiovento. (2ª ed.: 2019).

García Negro, M. Pilar (ed.) (2020). Ricardo Carvalho Calero, orador. Discursos e leccións. Santiago de Compostela: Parlamento de Galicia.

López, Aurora e Pociña, Andrés (2019). Rosalía de Castro nas obras de Ricardo Carballo Calero. Estudo bibliográfico. Follas Novas, 4, 176-194.

Mayoral, Marina (1974). La poesía de Rosalía de Castro. Madrid: Gredos.

Rodríguez, Francisco (2020). Abrindo camiño: o rosalianismo de Carvalho Calero. Sermos Galiza, 397, 22-25.

Rodríguez, Francisco (2020). Ricardo Carvalho Calero, mestre do rosalianismo. En: Ricardo Carvalho Calero, sempre con Galiza. Ferrol: Sociedade Cultural Medulio.

Salinas Portugal, Francisco (1991). Voz e siléncio (entrevista con R. Carvalho Calero). Vilaboa-Pontevedra: O Cumio. (2 ${ }^{\mathrm{a}}$ ed.: Santiago de Compostela: Laiovento, 2020).

Simmel, George (1934). Cultura femenina y otros ensayos. Madrid: Revista de Occidente. 